\title{
Editorial
}

\section{Dear ABCM community}

As announced in the last International Congress of Mechanical Engineering - COBEM (Gramado, December 2009), Prof. Paulo Miyagi finished his term as Editor-in-Chief of the Journal of the Brazilian Society of Mechanical Sciences and Engineering in December of 2009. The success of our journal, that has experienced a significant increase on its demand in the last few years, represents, with no doubts, a big achievement for our community. The consolidation of JBSMSE as a prestigious international journal, capable of competing within a dynamic scenario dominated by players connected to major publishers was made possible by personal efforts and commitment of many people. All started with Prof. Luiz Bevilacqua, the first Editor-in-Chief, in 1979. He was followed by Prof. Rubens Sampaio (1984), Prof. Hans Ingo Weber (1989), Prof. Leonardo Goldstein Jr. (1993), Prof. Átila Pantaleão Silva Freire (2000) and Prof. Paulo E. Miyagi (2006). Many other names should be remembered, including $\mathrm{ABCM}$ directors and Associated Editors.

JBSMSE being present in the main indexes (ISI, Compendex, Scopus, SciELO) is not only a sign of its quality and recognition by the scientific and technological community, but also entails big endeavors to be tackled in the near future. At this moment, JBSMSE is about to obtain its first impact factor from the Journal Citation Reports (JCR)/Science Edition. This factor reflects the way a journal impacts the overall advance of science within specific areas and fields. This is measured by the number of citations each article published receives along a timeframe of 3 years. Thus, in that sense, each one of us is made responsible for keeping JBSMSE in its relative position among the most prestigious journals.

At this time, I would also like to call your attention to the importance of SciELO Eletronic Library to JBSMSE. Not only it provides a means for improving the submission and review conditions for all agents involved (from authors to reviewers, not forgetting the precious work carried out by the Associate Editors) but also SciELO has made possible the access to our articles to be universal.

Finally, I would like to acknowledge the financial support of Brazilian funding agencies for JBSMSE. CNPq has been the leading agency on financing JBSMSE publication and it has been recently joined by FAPERJ and FAPEMIG on that. Particularly, the grant from a project coordinated by Prof. Domingos Rade from the Federal University of Uberlândia and awarded by FAPEMIG is covering the publication costs of the first two issues of this volume 32 .

Fernando A. Rochinha

Editor-in-Chief 